\title{
RISCO E VULNERABILIDADE DA BIODIVERSIDADE MARANHENSE RELACIONADOS AO CLIMA
}

\author{
Ainoã Perez Sousa Santos ${ }^{(1)}$, Luiz Cezar Franco Morais ${ }^{(2)}$, Ronaldo Rodrigues Araújo ${ }^{(3)}$;
}

${ }^{(1)}$ Departamento de Geociências, Universidade Federal do Maranhão, noanper@gmail.com

${ }^{(2)}$ Departamento de Geociências, Universidade Federal do Maranhão, luizcezar92@ hotmail.com

${ }^{(3)}$ Departamento de Geociências, Universidade Federal do Maranhão, ronaldo.araujo16@ gmail.com

Eixo: Climatologia em Diferentes Níveis escalares: Mudanças e Variabilidades

\section{Resumo}

No presente trabalho, abordaremos sobre os riscos e vulnerabilidade climáticos da biodiversidade do Maranhão, relacionando o comportamento de cada bioma que se manifesta no estado, quando este, encontra-se sujeito a efeitos de mudanças climáticas que modificam e conduzem a reprodução de um novo quadro no cenário que se apresenta atualmente. No geral, sabe-se que as variações climáticas podem gerar eventos extremos (secas anormais), desastres naturais (deslizamento de massa), risco socioambiental (residências em áreas de leito de excepcional de rios), entre outros elementos pertinentes.

Palavras chave: Riscos - Vulnerabilidade - Biodiversidade - Maranhão

\section{Metodologia}

Pesquisa qualitativa e exploratória, tendo em vista que será criada uma base de conhecimento, explicitando problemáticas referentes à biodiversidade no Maranhão, buscando uma compreensão do comportamento da mesma ao sofrer com alterações climáticas. Pesquisa de cunho bibliográfico, pois serão utilizados materiais já elaborados como base para o estudo (livros, artigos, relatórios, etc.).

\section{Reflexões sobre a Fauna e Flora Maranhense e suas Vulnerabilidades.}

A biodiversidade observada corresponde à fauna e a flora maranhense, que se encontram distribuídas em três biomas que estão sobre o território do estado: o Amazônico, Cerrado e a Caatinga. As mudanças que são observadas hoje causadas pelo EL Niño e a La Niña já evidenciam o efeito "devastador" que eventos climáticos podem gerar na biodiversidade que é vulnerável aos riscos que eles trazem consigo.

O estado se encontra no hemisfério sul próximo a linha do equador, com uma população de 6.574 .789 no censo de 2010 (IBGE, 2010). A maior densidade populacional se encontra no meio urbano do estado, sendo que muitas dessas pessoas estão em áreas de risco, como as áreas de encostas, no caso da sua capital, São Luís, e em áreas de deslizamentos de massa que é uma ameaça para os moradores desta 
região, que apresenta 60 áreas de risco segundo a Defesa Civil, o que com a intensidade de chuvas pode ser mais frequente.

Segundo Maranhão (2013, p. 99) a Caatinga ocupa cerca de 1,1\%, Amazônia 34,8\% e o Cerrado 64,1\% do estado, cada um desses biomas possuem características próprias, geradas de acordo com o solo, a vegetação, o relevo e o clima. O clima é um fator de suma importância pois este tem o poder de influenciar os outros fatores que compõe um sistema, o que não é diferente no Maranhão onde as mudanças podem afetar a reprodução da flora e a fauna.

Na Amazônia maranhense segundo a classificação de Thornthwaite (1948, apud Martins e Oliveira, 2011 p. 46-47) o clima predominante é:

Tabela 01 - Clima da Amazônia maranhense. Fonte: elaborado a partir de Thornthwaite (1948, apud Martins, 2011)

\begin{tabular}{|c|c|}
\hline Clima & Regiões climaticamente homogêneas \\
\hline Úmido subúmido tipo C2; & Município de Imperatriz; \\
\hline Úmido do tipo B1, B2 & $\begin{array}{c}\text { Municípios de São Luis, Zé Doca, } \\
\text { Turiaçu. }\end{array}$ \\
\hline
\end{tabular}

Ayoade (1996, p. 237) mostra que a classificação de Thornthwaite considera a evaporação potencial, a precipitação e a relação entre eles, fornecedora de critérios para esta classificação, sendo que na região de Imperatriz (tabela 01) a característica climática é subúmido chuvoso com índice de umidade entre 0-20 e nos municípios de São Luís, Zé Doca e Turiaçu de úmido B1 (20-40) e úmido B2 (40-60) assim as regiões próximas a zona costeira possuem maior índice de umidade.

O balanço hídrico é essencial, assim como a evapotranspiração potencial para a flora, e se ocorrer a falta de chuva na Amazônia maranhense, o retardamento no crescimento da planta será observado, devido a fatores bioquímicos e fisiológicos. Já se houver o excesso de chuva haverá o aparecimento de doenças e pragas nas plantas, prejudicando assim a produção de hortaliças e fruticulturas e no desenvolvimento das plantas em geral. Este último pode ainda intensificar os processos de lixiviação e erosão, causando o escoamento superficial e percolação do solo, havendo perda de nutrientes, prejudicando o desenvolvimento dos vegetais.

Notavelmente, a flora que se encontra na Amazônia maranhense está vulnerável as modificações no regime de precipitação, as espécies que a compõe sofreriam uma redução em sua população se houvesse a diminuição na precipitação média anual, já a umidade relativa do ar é elevada em comparação a outras regiões do estado, e com o aumento da temperatura dado a alguma mudança climática causada pelo El 
Niño, por exemplo, e com a intensificação desse evento, algumas espécies que estão hoje neste espaço podem não estar mais presentes, pois não estariam adaptadas a outras condições climáticas.

No Cerrado, a flora é xeromorfa, ou seja, adaptada a clima seco, sendo assim, o solo é lixiviado e aluminizado, consequentemente, o aumento da temperatura não afetará tanto esta vegetação que é adaptada a esse extremo, porém, estará mais sujeita a queimadas e uma falta de controle antrópico sobre este ambiente, considerando que estará com condições climáticas favoráveis a esse fenômeno, não excluindo a ação humana que pode ser responsável pelo fenômeno da queimada, o clima apenas favorece a maior probabilidade de sua ocorrência. (MARTINS e OLIVEIRA, 2011).

Existem áreas que apresentam baixa umidade relativa do ar, assim como na região da caatinga que se encontra a leste do estado. No caso do sul do estado a baixa umidade está relacionada ao efeito da continentalidade que é predominante, diferentemente da região norte do estado que sofre influência da maritimidade, assim como a região oeste onde se localiza a Amazônia maranhense, sendo ambientes onde a umidade relativa do ar é elevada em comparação ao cerrado.

A Caatinga é provavelmente o mais desvalorizado e mal conhecido botanicamente entre os biomas brasileiros, de acordo com Giulietti et al. (2004). No Maranhão, este bioma ocupa 1,1\% do estado, e é caracterizado pelo clima típico do nordeste brasileiro, semiárido, com elevadas temperaturas e baixa umidade. Possivelmente seria o menos atingido no estado, por ser uma área de menor ocorrência e por suas características climáticas já adaptadas a altas temperaturas, embora possa sofrer com queimadas, já comuns na área.

Assim, o clima pode influenciar na distribuição vegetal do estado e que uma mudança nas suas variáveis climáticas pode modificar a composição da flora maranhense. Há a possibilidade de um avanço da vegetação de cerrado sobre o bioma amazônico, caso ocorra um cenário de elevação das temperaturas e baixa pluviosidade, que favoreceria a savanização dessa região do estado, pois muitas espécies são totalmente adaptadas a ambientes úmidos.

O livro publicado pelo Ministério do Meio Ambiente sobre Mudanças climáticas globais e seus efeitos sobre a biodiversidade de Marengo (2006), fala sobre o que já ocorre no clima do nordeste brasileiro e o que pode suceder. A vulnerabilidade da biodiversidade do estado estudado se mostra, no que tange ao regime de chuvas, vazões de rios na Amazônia e no Nordeste e disponibilidade hídrica, interanual e interdecadal em escala de tempo.

Souza e Miranda (2013, p. 202) afirmam que Zona de Convergência intertropical é uma das responsáveis pela característica de elevados níveis de precipitação na região norte do país, ocasionando assim no 
Maranhão seu regime de chuvas e tempestades que associada ao efeito de eventos como El Niño e La Niña podem modificar este ciclo, dependendo da sua intensidade e frequência que o El Niño pode deixar o Maranhão sujeito a secas e a La Niña a chuvas intensas, ou seja, falamos que o excesso hídrico causa a propagação de doenças e pragas na flora e a escassez deste recurso ocasiona a falta de crescimento da flora devido à falta dos seus processos bioquímicos e fisiológicos necessários.

\subsection{Manguezais}

Se tratando de biodiversidade, é interessante falar a respeito dos ecossistemas costeiros, sobretudo dos manguezais, tendo em vista que: "É na Amazônia Costeira que se estende a maior área contínua de manguezais do mundo, com cerca de $8.900 \mathrm{~km}$, sendo que o litoral do estado do Maranhão, sozinho, compreende 50\% do total dessa área (KJERFVE et al. 2002 apud MARTINS e OLIVEIRA, 2011, p. 92).

Estas áreas são de grande importância para o equilíbrio do sistema ambiental do estado, tendo em vista que é um berçário para inúmeras espécies de peixes, aves, mamíferos, entre outros. Sendo assim, este ambiente pode ser muito frágil à grandes perturbações, como é o caso das mudanças climáticas, tendo em vista que muitas espécies da flora e da fauna apresentam baixa tolerância a um novo ambiente, principalmente as espécies endêmicas do local. Há muitas espécies da fauna em risco de extinção, e é importante frisar que há inúmeros fatores para isso, podendo ser por causas naturais ou por intervenções humanas, como, por exemplo, a pesca predatória e a ocupação desordenada dos manguezais.

Um bom exemplo do comportamento desse ecossistema é colocado por Martins (2011, p. 94): "Se a evaporação excede a precipitação há ocorrência de apicuns. Se a precipitação ultrapassa a evaporação, os ambientes de água doce predominam na transição entre os manguezais e a vegetação terrestre". Isto pode significar que se um cenário de aumento de temperatura vier a ocorrer futuramente, a tendência seria haver avanço de áreas de apicuns, pois são ambientes hipersalinos e mais adaptados a menor pluviosidade, acarretando mudanças na biodiversidade do estado. Já se houver aumento de pluviosidade, os manguezais seriam favorecidos com a maior recarga de água doce, recolonizando áreas ocupadas por apicuns.

\section{Considerações Finais}

Com tudo o que foi apresentado, o Maranhão por estar localizado na região Nordeste do Brasil está bastante vulnerável as variações climáticas que ocorrem em escala global. Com isso, a biodiversidade do estado responderá de alguma forma a essas mudanças. No caso dos biomas, pode haver um processo acelerado de savanização do estado, pois possíveis aumentos de temperatura e diminuição de pluviosidade favoreceriam este bioma em detrimento do amazônico, que depende da umidade para se manter fortalecido. 
XVII Simpósio Brasileiro

de Geografia Fisica Aplicada

I Congresso Nacional de Geografia Física
OS DESAFIOS DA GEOGRAFIA FÍSICA NA FRONTEIRA DO CONHECIMENTO

Instituto de Geociências - Unicamp

Campinas - SP

28 de Junho à 02 de Julho de 2017

Com relação a fauna, algumas hipóteses foram levantadas neste estudo, como a possibilidade de aceleração do processo de extinção que ameaça diversas espécies em cada bioma, inclusive nas áreas de conservação do estado, frisando que o clima agiria em conjunto com outros fatores, como o desmatamento, não sendo a única causa deste problema. Poderia também haver outras respostas das espécies, como a migração para um ambiente similar e menos adaptado, ou ainda processos de evolução e hibridização que poderiam ser melhor estudados (não há muitos dados referentes a essas possibilidades).

Fato é que quaisquer variações climáticas que venham afetar a biodiversidade do estado provocarão mudanças de cunho ecológico, ambiental, social e econômico. Políticas públicas são necessárias para apaziguar problemas que podem ser acelerados em caso de um cenário de mudança de temperatura, aliado a isto, deve haver conscientização do papel que a sociedade tem neste contexto e a compreensão de que esses processos são naturais e que a ação humana pode intensifica-los, o que o homem pode fazer é amenizar o que ele próprio já causou e buscar formas de adaptação ao ambiente.

\section{Bibliografia}

AYOADE, J. O. Introdução a climatologia para os trópicos; 4 ed. Rio de Janeiro: Bertrand Brasil, 1996. 237 p.

GIULIETTI, A. M.; et al. Diagnóstico da vegetação nativa do bioma Caatinga. In: SILVA, J. M. C.; TABARELLI, M.; FONSECA, M.T.; LINS, L. V. (Orgs). Biodiversidade da Caatinga: áreas e ações prioritárias para a conservação. Brasília, DF: MMA; UFPE; Conservation International do Brasil; Fundação Biodiversitas; Embrapa Semi-Árido, 2004. p. 48-90.

INSTITUTO BRASILEIRO DE GEOGRAFIA E ESTATÍSTICA, IBGE. Censo demográfico, 2010.

MARENGO, J. A. Mudanças climáticas globais e seus efeitos sobre a biodiversidade: caracterização do clima atual e definição das alterações climáticas para o território brasileiro ao longo do século XXI. Brasília: MMA, 2006.

MARTINS, M. B.; OLIVEIRA, T. G. Amazônia Maranhense: Diversidade e Conservação. Belém: MPEG, 2011. MARANHÃO. Relatório do Diagnostico do Macrozoneamento Ecológico-Econômico do Estado do Maranhão. Campinas, SP. Seplan-MA/Embrapa, 2013.

SOUZA, L. de; MIRANDA, R.A.C de. Climatologia Geográfica. Rio de Janeiro: Fundação CECIERJ, 2013. 202 p. v.1. 